\title{
CD74-ROS1 fusion transcripts in resected non-small cell lung carcinoma
}

\author{
SHUN MATSUURA $^{1,2}$, KAZUYA SHINMURA ${ }^{1}$, TAKAHARU KAMO ${ }^{1}$, HISAKI IGARASHI ${ }^{1}$, \\ KYOKO MARUYAMA $^{1}$, MARI TAJIMA ${ }^{1}$, HIROSHI OGAWA ${ }^{4}$, MASAYUKI TANAHASHI ${ }^{5}$, HIROSHI NIWA ${ }^{5}$, \\ KAZUHITO FUNAI ${ }^{3}$, TAKASHI KOHNO ${ }^{6}$, TAKAFUMI SUDA ${ }^{2}$ and HARUHIKO SUGIMURA ${ }^{1}$ \\ Departments of ${ }^{1}$ Tumor Pathology, ${ }^{2}$ Internal Medicine 2 and ${ }^{3}$ Surgery 1, Hamamatsu University School of Medicine, \\ Hamamatsu, Shizuoka 431-3192; Divisions of ${ }^{4}$ Pathology and ${ }^{5}$ Thoracic Surgery, Respiratory Disease Center, \\ Seirei Mikatahara General Hospital, Hamamatsu, Shizuoka 433-8558; ${ }^{6}$ Division of Genome Biology, \\ National Cancer Center Research Institute, Chuo-ku, Tokyo 104-0045, Japan
}

Received April 11,2013; Accepted June 7, 2013

DOI: 10.3892/or.2013.2630

\begin{abstract}
The recent discovery of fusion oncokinases in a subset of non-small cell lung carcinomas (NSCLCs) is of considerable clinical interest, since NSCLCs that express such fusion oncokinases are reportedly sensitive to kinase inhibitors. To better understand the role of recently identified ROS1 and RET fusion oncokinases in pulmonary carcinogenesis, we examined 114 NSCLCs for SLC34A2-ROS1, EZR-ROS1, CD74-ROS1 and KIF5B-RET fusion transcripts using RT-polymerase chain reaction and subsequent sequencing analyses. Although the expression of SLC34A2-ROS1, EZR-ROS1, or KIF5B-RET fusion transcripts was not detected in any of the cases, the expression of CD74-ROS1 fusion transcripts was detected in one $(0.9 \%)$ of the 114 NSCLCs. The fusion occurred between exon 6 of CD74 and exon 34 of ROS1 and was an in-frame alteration. The mutation was detected in a woman without a history of smoking. Histologically, the carcinoma was an adenocarcinoma with a predominant acinar pattern; notably, a mucinous cribriform pattern and a solid signet-ring cell pattern were also observed in part of the adenocarcinoma. ROS1 protein overexpression was immunohistochemically detected in a cancer-specific manner in both the primary cancer and the lymph node metastatic cancer. No somatic mutations were detected in the mutation cluster regions of the KRAS, EGFR, BRAF and PIK3CA genes and the entire coding region of $p 53$ in the carcinoma, and the expression of ALK fusion was negative. The above results suggest
\end{abstract}

Correspondence to: Dr Kazuya Shinmura, Department of Tumor Pathology, Hamamatsu University School of Medicine, 1-20-1 Handayama, Higashi Ward, Hamamatsu, Shizuoka 431-3192, Japan E-mail: kzshinmu@hama-med.ac.jp

Key words: fusion gene, non-small cell lung carcinoma, ROS1, CD74, RET, ALK that CD74-ROS1 fusion is involved in the carcinogenesis of a subset of NSCLCs and may contribute to the elucidation of the characteristics of ROS1 fusion-positive NSCLC in the future.

\section{Introduction}

The $A L K$ fusion gene is a key oncogenic driver in a subset of patients with non-small cell lung carcinomas (NSCLCs) (1-5). EML4-ALK, consisting of the N-terminal portion of EML4 ligated to the intracellular region of the receptor-type protein tyrosine kinase ALK, has been detected in $\sim 2-7 \%$ of NSCLC patients (1-6). EML4-ALK-positive NSCLC is associated with several characteristics, such as early-onset, a never- or light-smoking history, adenocarcinoma and mutual exclusiveness with $E G F R$ or KRAS mutations (7). Recently, crizotinib, a small molecule inhibitor of ALK, was shown to selectively inhibit the growth of ALK-positive NSCLC (6-8), indicating that a subclass of NSCLC patients are likely to benefit clinically from an ALK inhibitor. Therefore, molecular data regarding oncogenic fusion may have a significant clinical impact.

Both ROS1 and RET receptor tyrosine kinases have recently been identified as oncogenic fusions in NSCLC (4,5,9-17). The expression of these fusion proteins transforms noncancerous cells $(4,14)$. Among some types of such fusion forms, SLC34A2-ROS1, EZR-ROS1, CD74-ROS1 and KIF5B-RET are relatively recurrent $(4,5,9-17)$. However, since the incidence of ROS1 or RET fusions is less than that of ALK fusions in NSCLC, only a small number of NSCLC patients with ROS1 or RET fusions has thus far been identified. In the present study, to contribute to the elucidation of the characteristics of ROS1 or RET fusion-positive NSCLC, we examined 114 NSCLCs derived from Japanese patients for the expression of ROS1 and RET fusion transcripts and pathohistologically and molecularly characterized those fusions that were detected.

\section{Materials and methods}

Primary lung carcinoma. Samples of surgical specimens were obtained from 114 NSCLC patients who underwent surgery for 
cancer at Mikatahara Seirei General Hospital and Hamamatsu University Hospital. Informed consent to use the resected tissues for genetic analysis was obtained from all the patients and the study was approved by the Institutional Review Boards (IRBs) of Hamamatsu University School of Medicine and Mikatahara Seirei General Hospital. The clinicopathological profiles of the cases are shown in Table I. The staging and histological classification were based on the World Health Organization system.

Detection of ROS1 and RET gene fusion transcripts using reverse transcription $(R T)$-polymerase chain reaction $(P C R)$. Total RNA was extracted from the lung tissue samples using an RNeasy kit (Qiagen, Valencia, CA, USA) and was converted to first-strand cDNA using a SuperScript First-Strand Synthesis System for RT-PCR (Invitrogen, Carlsbad, CA, USA) according to the supplier's protocol. PCR was performed in $20-\mu 1$ reaction mixtures containing HotStarTaq DNA Polymerase (Qiagen). The following PCR primers were used: 5'-GGGATTGGGATATTGATTTTAC-3' and 5'-AGCTCA GCCAACTCTTTGTCT-3' for the SLC34A2-ROS1 fusion transcript; 5'-ACCGTGGAGAGAGAGAAAGAG-3' and 5'-AGCTCAGCCAACTCTTTGTCT-3' for the EZR-ROS1 fusion transcript; 5'-ATTGGCTCCTGTTTGAAATG-3' and 5'-TTATAAGCACTGTCACCCCTTC-3' for the CD74-ROS1 fusion transcript; and 5'-TCGGCAACTTTAGCGAGTAT-3' and 5'-TTCTCTTTCAGCATCTTCACG-3' for the KIF5B-RET fusion transcript. The PCR products were fractionated using electrophoresis on an agarose gel and were stained with ethidium bromide. PCR-amplified products were purified with ExoSAP-IT (GE Healthcare Bio-Science, Piscataway, NJ, USA) and were sequenced directly using a BigDye ${ }^{\circledR}$ Terminator Cycle Sequencing Reaction Kit and the ABI 3130 Genetic Analyzer (both from Applied Biosystems, Tokyo, Japan).

Immunohistochemical staining. Sections of formalin-fixed, paraffin-embedded tissue samples were used for immunohistochemical staining performed using the EnVision (Dako ChemMate) kit (Dako, Kyoto, Japan). The primary antibodies were as follows: anti-thyroid transcription factor-1 (TTF-1), anti-napsin A, anti-CK14 (all from Novocastra Laboratories, Newcastle, UK), anti-p63 (Japan Tanner, Osaka, Japan), anti-CD56 (Novocastra Laboratories), anti-chromogranin A (Dako), anti-synaptophysin (Novocastra Laboratories) and anti-ROS1 (clone D4D6; Cell Signaling Technology, Beverly, MA, USA). Hematoxylin and eosin (H\&E) staining was also performed.

Mutation search. Genomic DNA was extracted from the lung tissue samples containing ROS1 fusion transcripts using a DNeasy kit (Qiagen) and was examined for somatic mutations in the DNA sequences of mutation cluster regions (hot spots) in the KRAS, EGFR, BRAF and PIK3CA genes and in the entire coding sequence of the $p 53$ gene. PCR amplification was performed in $20-\mu 1$ reaction mixtures containing HotStarTaq DNA Polymerase (Qiagen). The following PCR primers were used: 5'-AAAGGTACTGGTGGAGTATTTG-3' and 5'-GTCCTGCACCAGTAATATGC-3' for KRAS (exon 2); 5'-AATCCAGACTGTGTTTCTCC-3' and 5'-ATATTATATC ATGGCATTAGC-3' for KRAS(exon 3); 5'-GCAATATCAGCC
Table I. Summary of the clinicopathological profiles of the patients.

\begin{tabular}{lc}
\hline Characteristic & $\mathrm{n}$ \\
\hline No. of patients & 114 \\
Age, years (mean \pm SD) & $68.5 \pm 6.0$ \\
Gender, n (\%) & \\
Male & $87(76.3)$ \\
Female & $27(23.7)$ \\
Smoking, n (\%) & \\
Current smokers & $49(43.0)$ \\
Ex-smokers & $37(32.5)$ \\
Non-smokers & $28(24.5)$ \\
Histology, n (\%) & \\
Adenocarcinoma & $69(60.5)$ \\
Squamous cell carcinoma & $39(34.2)$ \\
Adenosquamous cell carcinoma & $4(3.5)$ \\
Others & $2(1.8)$ \\
Stage, n (\%) & \\
I & $54(47.4)$ \\
II & $33(28.9)$ \\
III & $27(23.7)$ \\
IV & $0(0.0)$ \\
\hline
\end{tabular}

$\mathrm{SD}$, standard deviation.

TTAGGTGCGGTC-3' and 5'-CATAGAAAGTGAACATTTA GGATGTG-3' for EGFR (exon 19); 5'-CTAACGTTCGCCAGC CATAAGTCC-3' and 5'-GCTGCGAGCTCACCCAGAAT GTCTGG-3' for EGFR (exon 21); 5'-AATTTTTCTTAAG GGGATCTCTTCC-3' and 5'-GCGAACAGTGAATATTT CCTTTG-3' for BRAF (exon 11); 5'-ACCTAAACTCTTCAT AATGCTTGCTC-3' and 5'-CTTCAATGACTTTCTAGTAA CTCAGCAG-3' for BRAF (exon 15); 5'-TTAGATTGGTT CTTTCCTGTCTCTG-3' and 5'-TCCAATAGGTATGGTAA AAACATGC-3' for PIK3CA (exon 9); 5'-GTGACATT TGAGCAAAGACCTG-3' and 5'-CTGTTCATGGATTGT GCAATTC-3' for PIK3CA (exon 20); 5'-TTGGAAGTG TCTCATGCTGG-3' and 5'-AAGAGCAGTCAGAGGACC AGG-3' for $p 53$ (exons 2 and 3); 5'-ACCTGGTCCTCT GACTGCTC-3' and 5'-TTGAAGTCTCATGGAAGCCAG-3' for p53 (exon 4); 5'-TTGTGCCCTGACTTTCAACTC-3' and 5'-ACCAGCCCTGTCGTCTCTC-3' for p53 (exon 5); 5'-TCAGATAGCGATGGTGAGCAG-3' and 5'-GGAGGT CAAATAAGCAGCAGG-3' for $p 53$ (exon 6); 5'-CTCATC TTGGGCCTGTGTTATC-3' and 5'-GAAGAAATCGGTA AGAGGTGGG-3' for $p 53$ (exon 7); 5'-CTGCCTCTTGCTT CTCTTTTCC-3' and 5'-ACTTTCCACTTGATAAGAGGT CCC-3' for the $p 53$ (exons 8 and 9); 5'-ATACTTACTTCT CCCCCTCCTCTG-3' and 5'-GGATGAGAATGGAATCCT ATGG-3' for $p 53$ (exon 10); and 5'-TGATGTCATCTC TCCTCCCTG-3' and 5'-TTGCAAGCAAGGGTTCAAAG-3' for $p 53$ (exon 11). Sequencing was performed as described above. 
A

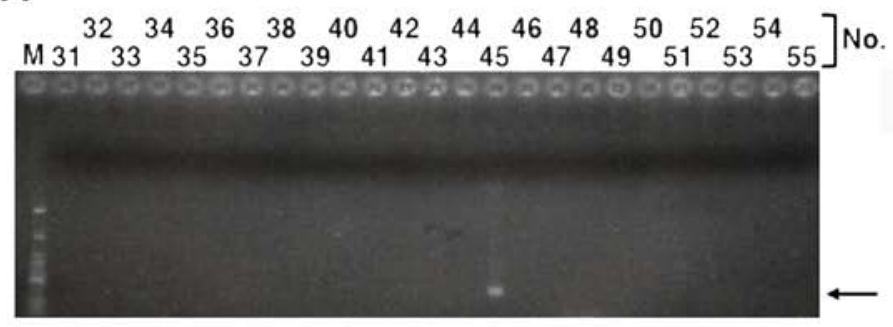

B

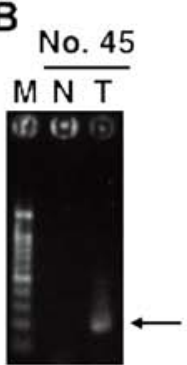

C

\begin{tabular}{l|l} 
CD74 exon 6 & ROS1 exon 34
\end{tabular} TCCAC C G AAAGAT GAT T T T T G G

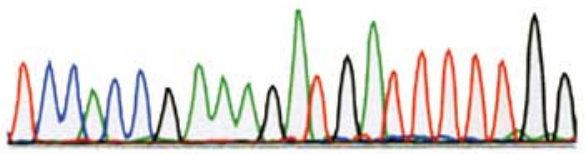

Figure 1. Detection of CD74-ROS1 fusion transcripts in a non-small cell lung carcinoma (NSCLC). (A) cDNA derived from cancerous tissue of NSCLC was searched for fusion transcripts using RT-polymerase chain reaction (PCR) and subsequent agarose gel electrophoresis. A specific band was detected in case no. 45 using RT-PCR with a set of primers for the sequence at CD74 and at ROS1. The arrow indicates the PCR product. (B) RT-PCR analysis of cDNA derived from $\mathrm{N}$ and $\mathrm{T}$ in case no. 45 for the detection of CD74-ROS1 fusion transcripts. The arrow indicates the PCR product. (C) Sequencing analysis of the CD74-ROS1 fusion transcripts. A sequencing electropherogram showed the fusion occurred between exon 6 of CD74 and exon 34 of ROS1. M, size marker; $\mathrm{N}$, non-cancerous tissue; $\mathrm{T}$, cancerous tissue.
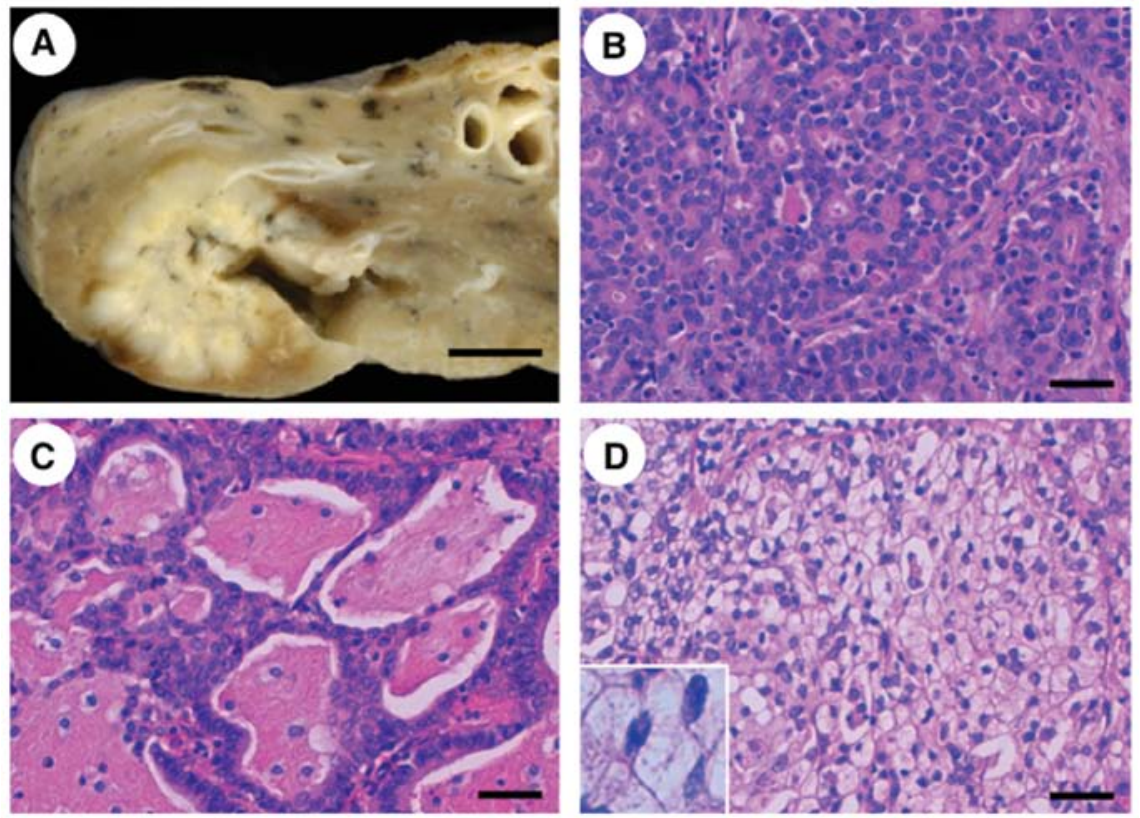

Figure 2. Pathohistological examination of non-small cell lung carcinoma (NSCLC) containing the CD74-ROS1 fusion transcript. (A) Macroscopic image of the lung carcinoma in case no. 45. A well-delineated, white, solid mass was seen in the lung parenchyma. (B) An acinar pattern was predominantly observed in this adenocarcinoma. (C) A cribriform structure associated with abundant extracellular mucus (mucinous cribriform pattern) was observed in a portion of the carcinoma. (D) A solid growth pattern containing signet-ring cells (solid signet-ring cell pattern) was observed in a portion of the carcinoma. The inset shows a magnified image of the signet-ring cells. (B-D) Hematoxylin and eosin stain. Scale bar, (A) $1 \mathrm{~cm}$ and (B-D) $50 \mu \mathrm{m}$.

Detection of ALK gene fusion transcripts using RT-PCR. PCR was performed in 20- $\mu$ l reaction mixtures containing HotStarTaq DNA Polymerase (Qiagen) under the following conditions: $30 \mathrm{sec}$ at $94^{\circ} \mathrm{C}, 30 \mathrm{sec}$ at $61^{\circ} \mathrm{C}$ and $70 \mathrm{sec}$ at $72^{\circ} \mathrm{C}$ for 45 cycles. A total of five different PCR-primer pairs for EML4-ALK and three PCR-primer pairs for KIF5B-ALK were used for the RT-PCR. The forward PCR primers were: 5'-CAAGATGGACGGTTTCGCCGGCAGTCTCG-3' for the sequence at exon 1 of EML4; 5'-ACAAATTCGAGCATC ACCTTCTCC-3' for the sequence at exon 4 of EML4; 5'-GTG CAGTGTTTAGCATTCTTGGGG-3' for the sequence at exon 13 of EML4; 5'-CTGTGGGATCATGATCTGAATC CTG-3' for the sequence at exon 14 of EML4; 5'-CTTCCT GGCTGTAGG ATCTCATGAC-3' for the sequence at exon 19 of EML4; 5'-CACTATTGTAATTTGCTGCTCTCCATC ATC-3' for the sequence at exon 10 of KIF5B; 5'-AATCTG
TCGATGCCCTCAGTGAAG-3' for the sequence at exon 17 of KIF5B; and 5'-TGATCGCAAACGCTATCAGCAAG-3' for the sequence at exon 24 of KIF5B. The reverse PCR primer used was the same, i.e., 5'-GAGGTCTTGCCAGCAAAG CAGTAG-3' for the sequence at exon 20 of ALK.

\section{Results}

In the present study, 114 NSCLCs were examined for SLC34A2-ROS1, EZR-ROS1, CD74-ROS1 and KIF5B-RET fusion transcripts using RT-PCR and subsequent sequencing analyses. Although the expression of SLC34A2-ROS1, EZR-ROS1 and KIF5B-RET fusion transcripts was not detected in any of the carcinomas, CD74-ROS1 fusion transcripts were detected in one $(0.9 \%)$ NSCLC (Fig. 1). The CD74-ROS1 fusion transcripts were expressed in the 

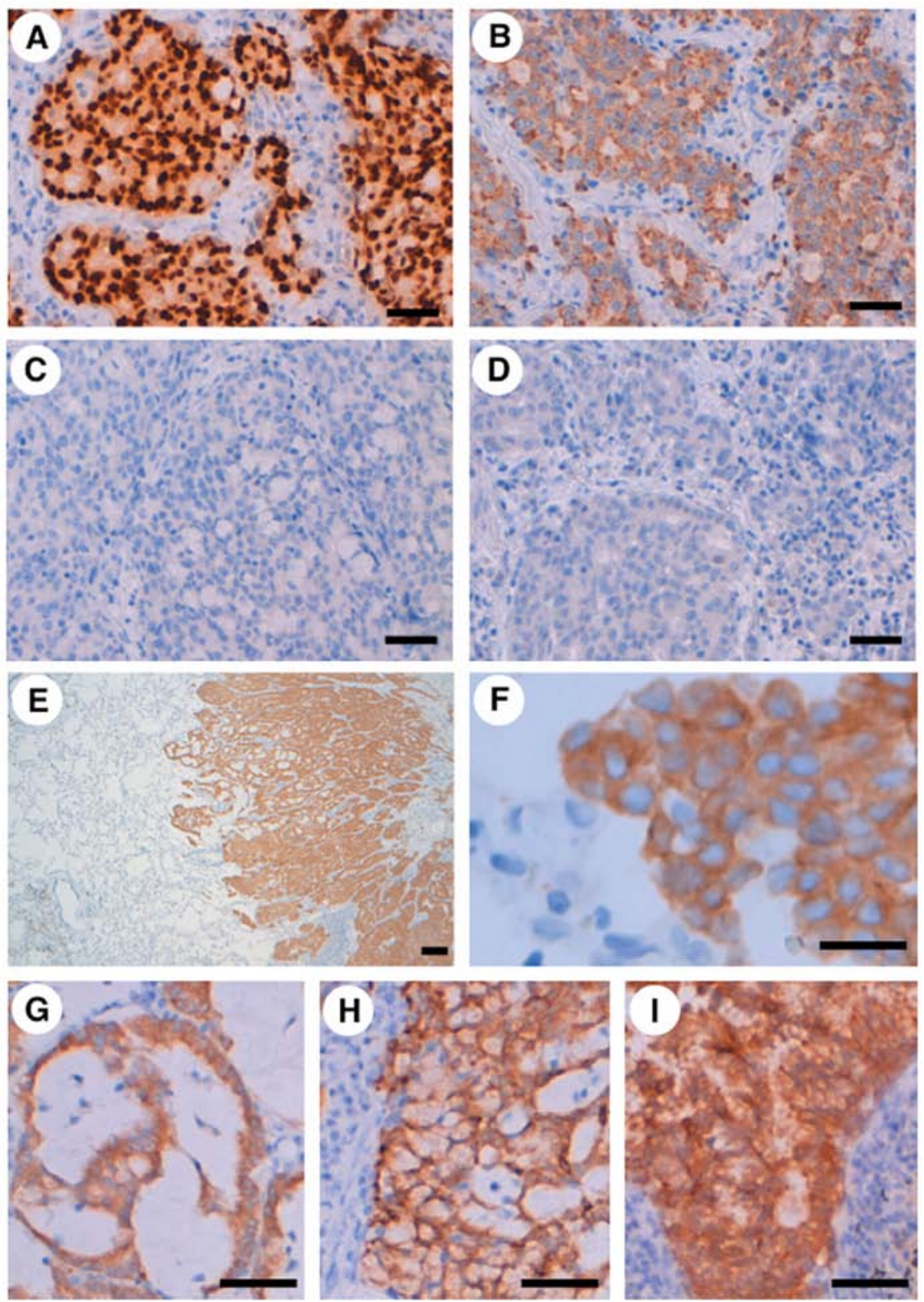

Figure 3. Immunohistochemical analysis of non-small cell lung carcinoma containing the CD74-ROS1 fusion transcript. The adenocarcinoma was immunohistochemically positive for (A) TTF-1 and (B) napsin A. The adenocarcinoma was immunohistochemically negative for (C) p63 and (D) chromogranin A. (E and F) The cancer-specific expression of ROS1 protein was detected. ROS1 protein was overexpressed specifically in the cytoplasm of the cancerous cells. Increased ROS1 expression in the (G) mucinous cribriform pattern and (H) solid signet-ring cell pattern of the adenocarcinoma. (I) Increased ROS1 expression in an adenocarcinoma that has metastasized to the mediastinal lymph node. Scale bar, (A-D and G-I) $50 \mu \mathrm{m},(\mathrm{E}) 200 \mu \mathrm{m}$ and (F) $20 \mu \mathrm{m}$.

cancerous tissues but not in the non-cancerous tissues in the NSCLC case (case no. 45) (Fig. 1B). Sequencing of the RT-PCR product revealed that the fusion was between exon 6 of CD74 and exon 34 of ROS1 (Fig. 1C). The fusion was in-frame and allowed the transmembrane domain and the kinase domain of ROS1 to be retained. Case no. 45 was a 71-year-old woman who was a never-smoker. The NSCLC in this case was well-delineated and $3.0 \mathrm{~cm}$ in diameter (Fig. 2A). The histological classification was adenocarcinoma with a predominantly acinar pattern (Fig. 2B); a cribriform structure associated with abundant extracellular mucus (mucinous cribriform pattern) (Fig. 2C) and a solid growth pattern containing signet-ring cells (solid signet-ring cell pattern) (Fig. 2D) were partly observed. An immunohistochemical study revealed that the adenocarcinoma was positive for TTF-1 and napsin A, but negative for CK14, p63, CD56, chromogranin A and synaptophysin (Fig. 3A-D), indicating that immunophenotype of the carcinoma was compatible with adenocarcinoma without neuroendocrine features. Furthermore, the cancer-specific overexpression of the ROS1 protein was detected using an immunohistochemical analysis (Fig. 3E-I), in agreement with the cancer-specific expression of the ROS1 fusion mRNA transcript (Fig. 1B). An increased ROS1 protein signal was detected diffusely in the adenocarcinoma, including the mucinous cribriform pattern, and solid signet-ring cell pattern and the ROS1 protein was localized in the cytoplasm of the carcinoma cells (Fig. 3E-H). ROS1 protein was also highly expressed in the adenocarcinoma metastases to the lymph 
node (Fig. 3I). Additionally, after the surgical treatment, a brain metastasis of the adenocarcinoma was observed in the patient. The above findings suggest that CD74-ROS1 fusion transcripts are expressed in a subset of NSCLCs.

We next examined whether the NSCLC case containing the CD74-ROS1 fusion transcripts also contained previously reported driver mutations. Mutation cluster regions for $K R A S$, EGFR, BRAF and PIK3CA (18-20) were searched for somatic mutations and the expression of EML4-ALK and KIF5B-ALK fusion transcripts (1-5) was examined; however, no somatic mutations in exons 2 and 3 of $K R A S$, exons 19 and 21 of $E G F R$, exons 11 and 15 of $B R A F$, or exons 9 and 20 of $P I K 3 C A$ and no expression of EML4-ALK or KIF5B-ALK fusion transcripts were detected. We also performed a mutational analysis of the entire coding region of p53 of the carcinoma that contained CD74-ROS1 fusion transcripts. The case was found to be heterozygous for the Arg and Pro alleles of the p53 p.Arg72Pro genetic polymorphism, which is associated with a functional difference (21); however, no somatic p53 mutations were detected.

\section{Discussion}

In the present study, the expression of CD74-ROS1 fusion transcripts was found in one $(0.9 \%)$ of the 114 NSCLCs that were examined, but the expression of SLC34A2-ROS1, EZR-ROS1, or KIF5B-RET fusion transcripts was not detected in any of the NSCLCs. The detected fusion occurred between exon 6 of CD74 and exon 34 of ROS1 and was observed in a non-smoker female. Histologically, the carcinoma was an adenocarcinoma with a predominant acinar pattern; a mucinous cribriform pattern and a solid signet-ring cell pattern were also observed in a portion of the adenocarcinoma. ROS1 protein was overexpressed in a cancer-specific manner at both the primary site and the lymph node metastases. No somatic mutations were detected in the mutation cluster regions of the $K R A S$, EGFR, BRAF and PIK3CA genes and the entire coding region of $p 53$ in the carcinoma, and the expression of EML4- and KIF5B-ALK fusions was also not detected. These results suggest that CD74-ROS1 fusion contributes to the carcinogenesis of this NSCLC case as a driver mutation.

To date, ROS1 fusion transcripts have been detected in 0.7-1.9\% of NSCLC patients (Chinese, Japanese, white and Caucasian populations) $(5,9,10,12,14,15,17)$. The analytical methods used in the above-mentioned reports varied and RT-PCR, fluorescence in situ hybridization and immunohistochemical analyses have been used to search for NSCLCs containing ROS1 fusion products $(5,9,10,12,14,15,17)$. Considering our results ( $0.9 \%$ of Japanese NSCLC patients) and the results of the above-mentioned previous papers, racial differences in the frequency of ROS1 fusion-positive NSCLC are thought to be minimal, although distinct analytical methods were used in the various reports. Approximately 1.6 million new lung cancers are diagnosed each year worldwide (22); if NSCLC comprises $90 \%$ of these cancers, 1.45 million new cases of NSCLC are diagnosed every year. Since the prevalence of ROS1 fusion is $\sim 1 \%$ of all NSCLCs, $\sim 14,500$ new patients have ROS1 fusion-positive NSCLC. Recently, ROS1 inhibition was shown to lead to the suppression of the proliferation of cells containing ROS1 fusion in vitro $(12,14)$; furthermore, crizotinib, a small molecule inhibitor against ROS1 kinase in addition to ALK kinase, was shown to exhibit antitumor properties in a patient with NSCLC containing an ROS1 fusion $(12,14)$. Thus, patients with ROS1 fusion-positive NSCLC may comprise a novel subclass that could benefit clinically from ROS1 inhibition.

In our CD74-ROS1 fusion-positive case, no other oncogenic driver mutations were detected. Oncogenic driver mutations are responsible for the initiation and progression of NSCLCs, and they differ from passenger mutations in that they are also found within the cancer genomes but exist as a by-product of cancer cell development $(10,13,18,19)$. In general, oncogenic driver mutations are mutually exclusive (10). ROS1 fusion-positive cases reported in two previous studies $(4,17)$ were negative for alterations in the $A L K, R E T, E G F R$ and $K R A S$ genes. Thus, our results for the driver mutation search are compatible with the results of these previous reports, suggesting that ROS1 fusion is mutually exclusive with other oncogenic driver mutations in NSCLC.

A mucinous cribriform pattern and a solid signet-ring cell pattern were observed in a portion of the adenocarcinoma in the present case. Yoshida et al (17) recently reported that one-third of ROS1 fusion-positive NSCLCs contain a mucinous cribriform pattern and one-third contain a solid signet-ring cell pattern. Of note, both patterns are frequently observed in ALK-rearranged NSCLC $(4,23,24)$. Thus, both a mucinous cribriform pattern and a solid signet-ring cell pattern may be common pathohistological characteristics of ROS1 and ALK fusion-positive NSCLCs. We also showed that the ROS1 protein was highly expressed in both histological patterns in our case, and an increased ROS1 protein expression in both components has not previously been demonstrated, suggesting a novel finding of the present study. These results indicate that ROS1 is involved in the morphogenesis of the patterns.

EGFR mutations and EML4-ALK fusions are preferentially associated with NSCLC in non-smokers $(4,18,19)$. Our CD74-ROS1 fusion-positive case was a never-smoker. In three previous reports, ROS1 fusion was frequently found in the NSCLCs of never-smokers $(4,12,17)$; however, this characteristic was not detected in another report (14). The accumulation of ROS1 fusion-positive cases with information on the smoking history is required to better understand the role of ROS1 fusion in NSCLCs.

In conclusion, our CD74-ROS1 fusion-positive NSCLC in conjunction with previously detected ROS1 fusion-positive NSCLCs suggested that ROS1 fusion is involved in the carcinogenesis of a subset of NSCLCs and may significantly aid in elucidating the characteristics of ROS1 fusion-positive NSCLC in the future.

\section{Acknowledgements}

The authors acknowledge Ms. S. Izumo (Hamamatsu University School of Medicine) for her technical assistance. The present study was supported in part by a Grant-in-Aid from the Ministry of Health, Labour and Welfare (21-1), a Grantin-Aid from the Japan Society for the Promotion of Science (22590356), a Grant-in-Aid from the Ministry of Education, Culture, Sports, Science and Technology (221S0001) and the Smoking Research Foundation. 


\section{References}

1. Soda M, Choi YL, Enomoto M, Takada S, Yamashita Y, Ishikawa S, Fujiwara S, Watanabe H, Kurashina K, Hatanaka H, Bando M, Ohno S, Ishikawa Y, Aburatani H, Niki T, Sohara Y, Sugiyama Y and Mano H: Identification of the transforming EML4-ALK fusion gene in non-small-cell lung cancer. Nature 448: 561-566, 2007.

2. Shinmura K, Kageyama S, Tao H, Bunai T, Suzuki M, Kamo T, Takamochi K, Suzuki K, Tanahashi M, Niwa H, Ogawa H and Sugimura H: EML4-ALK fusion transcripts, but no NPMTPM3-, CLTC-, ATIC-, or TFG-ALK fusion transcripts, in non-small cell lung carcinomas. Lung Cancer 61: 163-169, 2008.

3. Shinmura K, Kageyama S, Igarashi H, Kamo T, Mochizuki T, Suzuki K, Tanahashi M, Niwa H, Ogawa H and Sugimura H: EML4-ALK fusion transcripts in immunohistochemically ALK-positive non-small cell lung carcinomas. Exp Ther Med 1: 271-275, 2010.

4. Takeuchi K, Soda M, Togashi Y, Suzuki R, Sakata S, Hatano S, Asaka R, Hamanaka W, Ninomiya H, Uehara H, Lim Choi Y, Satoh Y, Okumura S, Nakagawa K, Mano H and Ishikawa Y: RET, ROS1 and ALK fusions in lung cancer. Nat Med 18: 378-381, 2012.

5. Lipson D, Capelletti M, Yelensky R, Otto G, Parker A, Jarosz M, Curran JA, Balasubramanian S, Bloom T, Brennan KW, Donahue A, Downing SR, Frampton GM, Garcia L, Juhn F, Mitchell KC, White E, White J, Zwirko Z, Peretz T, Nechushtan H, Soussan-Gutman L, Kim J, Sasaki H, Kim HR, Park SI, Ercan D, Sheehan CE, Ross JS, Cronin MT, Jänne PA and Stephens PJ: Identification of new ALK and RET gene fusions from colorectal and lung cancer biopsies. Nat Med 18: 382-384, 2012.

6. Casaluce F, Sgambato A, Maione P, Rossi A, Ferrara C, Napolitano A, Palazzolo G, Ciardiello F and Gridelli C: ALK inhibitors: a new targeted therapy in the treatment of advanced NSCLC. Target Oncol 8: 55-67, 2013.

7. Shaw AT and Solomon B: Targeting anaplastic lymphoma kinase in lung cancer. Clin Cancer Res 17: 2081-2086, 2011.

8. O'Bryant CL, Wenger SD, Kim M and Thompson LA: Crizotinib: a new treatment option for ALK-positive non-small cell lung cancer. Ann Pharmacother 47: 189-197, 2013.

9. Rikova K, Guo A, Zeng Q, Possemato A, Yu J, Haack H, Nardone J, Lee K, Reeves C, Li Y, Hu Y, Tan Z, Stokes M, Sullivan L, Mitchell J, Wetzel R, Macneill J, Ren JM, Yuan J, Bakalarski CE, Villen J, Kornhauser JM, Smith B, Li D, Zhou X Gygi SP, Gu TL, Polakiewicz RD, Rush J and Comb MJ: Global survey of phosphotyrosine signaling identifies oncogenic kinases in lung cancer. Cell 131: 1190-1203, 2007.

10. Li C, Fang R, Sun Y, Han X, Li F, Gao B, Iafrate AJ, Liu XY, Pao W, Chen $\mathrm{H}$ and Ji H: Spectrum of oncogenic driver mutations in lung adenocarcinomas from East Asian never smokers. PLoS One 6: e28204, 2011.

11. Kohno T, Ichikawa H, Totoki Y, Yasuda K, Hiramoto M, Nammo T, Sakamoto H, Tsuta K, Furuta K, Shimada Y, Iwakawa R, Ogiwara H, Oike T, Enari M, Schetter AJ, Okayama H, Haugen A, Skaug V, Chiku S, Yamanaka I, Arai Y, Watanabe S, Sekine I, Ogawa S, Harris CC, Tsuda H, Yoshida T, Yokota $\mathrm{J}$ and Shibata T: KIF5B-RET fusions in lung adenocarcinoma. Nat Med 18: 375-377, 2012.
12. Bergethon K, Shaw AT, Ou SH, Katayama R, Lovly CM, McDonald NT, Massion PP, Siwak-Tapp C, Gonzalez A, Fang R, Mark EJ, Batten JM, Chen H, Wilner KD, Kwak EL, Clark JW, Carbone DP, Ji H, Engelman JA, Mino-Kenudson M, Pao W and Iafrate AJ: ROS1 rearrangements define a unique molecular class of lung cancers. J Clin Oncol 30: 863-870, 2012.

13. Seo JS, Ju YS, Lee WC, Shin JY, Lee JK, Bleazard T, Lee J, Jung YJ, Kim JO, Shin JY, Yu SB, Kim J, Lee ER, Kang CH, Park IK, Rhee H, Lee SH, Kim JI, Kang JH and Kim YT: The transcriptional landscape and mutational profile of lung adenocarcinoma. Genome Res 22: 2109-2119, 2012.

14. Davies KD, Le AT, Theodoro MF, Skokan MC, Aisner DL, Berge EM,Terracciano LM, Cappuzzo F, Incarbone M, Roncalli M, Alloisio M, Santoro A, Camidge DR, Varella-Garcia M and Doebele RC: Identifying and targeting ROS1 gene fusions in non-small cell lung cancer. Clin Cancer Res 18: 4570-4579, 2012.

15. Rimkunas VM, Crosby KE, Li D, Hu Y, Kelly ME, Gu TL, Mack JS, Silver MR, Zhou X and Haack H: Analysis of receptor tyrosine kinase ROS1-positive tumors in non-small cell lung cancer: identification of a FIG-ROS1 fusion. Clin Cancer Res 18: 4449-4457, 2012.

16. Yokota K, Sasaki H, Okuda K, Shimizu S, Shitara M, Hikosaka Y, Moriyama S, Yano M and Fujii Y: KIF5B/RET fusion gene in surgically-treated adenocarcinoma of the lung. Oncol Rep 28: $1187-1192,2012$.

17. Yoshida A, Kohno T, Tsuta K, Wakai S, Arai Y, Shimada Y, Asamura H, Furuta K, Shibata T and Tsuda H: ROS1-rearranged lung cancer: a clinicopathologic and molecular study of 15 surgical sases. Am J Surg Pathol 37: 554-562, 2013.

18. Schmid K, Oehl N, Wrba F, Pirker R, Pirker C and Filipits M: EGFR/KRAS/BRAF mutations in primary lung adenocarcinomas and corresponding locoregional lymph node metastases. Clin Cancer Res 15: 4554-4560, 2009.

19. Pao W and Girard N: New driver mutations in non-small-cell lung cancer. Lancet Oncol 12: 175-180, 2011.

20. Ulivi P, Romagnoli M, Chiadini E, Casoni GL, Capelli L, Gurioli C, Zoli W, Saragoni L, Dubini A, Tesei A, Amadori D and Poletti V: Assessment of EGFR and K-ras mutations in fixed and fresh specimens from transesophageal ultrasound-guided fine needle aspiration in non-small cell lung cancer patients. Int $\mathbf{J}$ Oncol 41: 147-152, 2012.

21. Thomas M, Kalita A, Labrecque S, Pim D, Banks L and Matlashewski G: Two polymorphic variants of wild-type p53 differ biochemically and biologically. Mol Cell Biol 19: 1092-1100, 1999.

22. Jemal A, Bray F, Center MM, Ferlay J, Ward E and Forman D: Global cancer statistics. CA Cancer J Clin 61: 69-90, 2011.

23. Rodig SJ, Mino-Kenudson M, Dacic S, Yeap BY, Shaw A, Barletta JA, Stubbs H, Law K, Lindeman N, Mark E, Janne PA, Lynch T, Johnson BE, Iafrate AJ and Chirieac LR: Unique clinicopathologic features characterize ALK-rearranged lung adenocarcinoma in the western population. Clin Cancer Res 15: 5216-5223, 2009

24. Jokoji R, Yamasaki T, Minami S, Komuta K, Sakamaki Y, Takeuchi K and Tsujimoto M: Combination of morphological feature analysis and immunohistochemistry is useful for screening of EML4-ALK-positive lung adenocarcinoma. J Clin Pathol 63: 1066-1070, 2010. 